\title{
Promoting next generation network investment through adapted performance indices
}

\author{
Mathieu Tahon, Koen Casier, Sofie Verbrugge, Didier Colle, Mario Pickavet \\ Information Based Communication Networks and Services \\ Ghent University - IBBT \\ Ghent, Belgium \\ mathieu.tahon@intec.ugent.be
}

\begin{abstract}
Broadband has been identified as a driver for economic growth, and the rollout of these networks is as such of key importance for Europe. Still, the observed rollout speed of NGAN networks is slower in Europe compared to the United States and Asia. The European Commission has identified this need and focuses on broadband coverage and high internet use penetration in its Digital Agenda for Europe. On national level, government and regulators have a twofold objective, translating this EU policy and stimulating competition in the retail market. Performance indices exist to visualize and quantify the performance of national and regional markets. These indices are typically used to show the historic performance of broadband markets. However, future oriented indices should be used to assess the impact of regulatory decisions on social welfare and on other market parties. We introduce such an index and show how it results in other regulatory outcomes compared with existing indices, in the case of wholesale access pricing.
\end{abstract}

Keywords-component; NGAN; performance indices; wholesale access pricing

\section{EUROPEAN AND NATIONAL BROADBAND POLICY}

Broadband has been identified as a driver for economic growth, and the rollout of these networks is as such of key importance for Europe. The European Commission drafted the Digital Agenda for Europe, introducing several targets for the period 2013 - 2020 concerning broadband [1]. For example, full broadband coverage with minimum speeds of $30 \mathrm{Mbps}$ and $50 \%$ of subscribers having speeds of $100 \mathrm{Mbps}$ are two main targets for 2020. For 2015, the Digital Agenda targets look to stimulate internet use, by setting targets for the use of eServices like eCommerce or eGovernment. For 2013, focus is on full broadband coverage. Here, broadband is defined as speeds equal or higher than $144 \mathrm{Kbps}$.

While the Digital Agenda focuses on broadband use and coverage, this is only one aspect of the objectives of national regulatory authorities (NRA). Improving competition and competitive broadband prices are two other goals they strive for. The former monopolistic incumbents were forced to open up their network for new entrants, the so-called other licensed operators (OLOs). Access to the copper network is based on regulated access prices, both for local loop unbundling (LLU) and bitstream access (BA). The debate about these regulated prices is still ongoing. From a competition perspective, LLU and BA prices as low as possible decrease the entry barrier for new entrants. Additionally, lower LLU prices also have an effect on the retail prices. A reduced LLU or BA price could be reflected in the final retail offer of OLOs to the end consumer. By adopting a lower price strategy, these OLOs can attract extra customers, which may decrease the significant market power of the incumbent.

Next to their impact on competition and retail price level, it has been argued that LLU prices also affect the investment behaviour of the incumbent in next generation access networks (NGAN). In [2], a decreasing copper wholesale access price is favoured, as this would stimulate broadband investment. By decreasing the profit of the incumbent in the copper market, lower LLU prices force the incumbent to find more attractive markets. Since the NGAN market promises higher average revenues per user (ARPU), an investment in this market should turn out to be more rewarding for the incumbent.

Although this effect might certainly be observed, there could be secondary effects which also influence the investment behaviour of the incumbent. Investment in NGAN requires a higher ARPU compared to existing services for the incumbent to be an economically interesting decision. But when the LLU price decrease is reflected in the retail prices offered by OLOs, this could result in a significant price difference between the copper and NGAN offer [3]. Rational users could prefer the 'same product for less money' copper offer over the 'better offer for the same money' offer of NGAN. While there will obviously be users preferring the NGAN offer, there might be a negative impact of the lower copper retail price on the viability of the NGAN business case. Recently, empirical research indicated the negative effects of copper unbundling on broadband deployment [4].

Additionally, there is extra uncertainty surrounding the investment climate for the incumbent. It is unclear what the future regulation will be concerning the NGAN networks. Will they be required to open up the NGAN network to new entrants, or will there be a regulatory holiday? What will be the future decisions on the LLU and BA prices? This uncertainty results in the postponement of the investment in NGAN, with operators exercising their option to wait.

Taking all these (sometimes opposite) effects into account, it is thus important for NRAs and European policy makers to have adequate instruments to measure the effect of their 
decisions. Performance indices (PI) are one of the tools to measure these effects. However, these are typically used ex post to assess the impact of previous policy. In this work, it will be shown how PIs can be used to compare alternative regulatory policies. After a short description of two existing PIs, each with their own shortcomings, we will introduce a new broadband performance index (BPI). This new BPI is capable of making a quantitative trade-off between different regulatory objectives. The performance of this new BPI will be assessed in a case of wholesale access pricing regulation, showing how different PIs result in different outcomes.

\section{THE TELECOM MARKET AND EVOLUTION}

The current evolution in fixed access networks is one of continuous increase of demand of bandwidth by users. IPTV, video services and other bandwidth hungry applications push the need for higher speeds in the access network. The introduction of 3DTV channels will raise the need for higher access speed even further.

Currently, incumbent operators possess a nationwide copper access network, which has in most cases already been upgraded towards Fibre to the Central Office, allowing to offer ADSL services, with download speeds between $8 \mathrm{Mbps}$ and 24 Mbps. Most incumbents are now upgrading this network to Fibre to the Cabinet (FttC) networks, which can offer even higher access speeds through VDSL. In some countries, cable operators are also present, who offer broadband services over a Hybrid Fibre Coax (HFC) network, using DOCSIS 2.0 and offering speeds up to $30 \mathrm{Mbps}$.

However, these networks are reaching their limits and require upgrading towards higher up- and download speeds. Cable networks can be upgraded towards the DOCSIS 3.0 standard, which can reach download speeds up to $100 \mathrm{Mbps}$. The current FttC incumbent networks also still offer room for improvement without cost intensive physical infrastructure upgrades. New techniques, like shadowing and vectoring can stretch the download speeds towards 50 Mbps. Although both copper and cable networks have currently not reached their limits, continuous bandwidth demand growth will in the long run result in the need for more fibre rich networks, like Fibre to the Building (FttB) or even Fibre to the Home (FttH). In contrast with the existing networks, these can offer symmetrical access speeds starting at $60 \mathrm{Mbps}$, with upgrade possibilities up to $1 \mathrm{Gbps}$.

\section{A. The role and objectives of telecom regulation}

National regulatory authorities have to take a plethora of objectives and effects into account when taking regulatory decisions. One of the major issues in the last decade has been the unbundling of the access network. Originally, these networks were installed for providing voice signal transmission, but technologic evolution also allowed data transmission over these networks. As technology continued to evolve, data transmission became even more important. However, these networks continued to be (partly) publicly owned, keeping off all competition in the field, except for infrastructure based competition via a cable network.

With privatization of the sector also came decoupling of the incumbent network operators from direct government control.
Still, since these operators possessed the existing network infrastructure, which was installed and paid for during the public period, they continued to have a large competitive advantage over new entrants. To clear this historic advantage, a level playing field needed to be installed, requiring incumbents to open up their network to other operators at regulated prices. This price is based on an estimation of the maintenance costs of this network for the incumbent. In extension, the operator might also be forced to open up at the data link layer which is often called bitstream access [5]. In theory, the network can be opened up at each level of functionality of the OSI layered model. For a copper access network, this is typically done on the lowest three layers. In case of full unbundling, the incumbent patches the copper pair of the customer directly to OLO equipment. The OLO has full access to the physical medium at OSI layer 0 . In case of shared line, the voice signal is separated from data by leading the copper pair to a splitter. Each signal can then be brought to the incumbent or OLO. This way, the physical OSI layer 1 is defined for both voice and data. In case of BA, voice is split from data in the central office. The data is sent into the metro network to aggregation switches, or Points of Presence (PoP) where the OLO can collocate his equipment. The connection from these PoPs is handles through OSI layer 2 or 3 . In figure 1 , an overview of the different possibilities can be found.

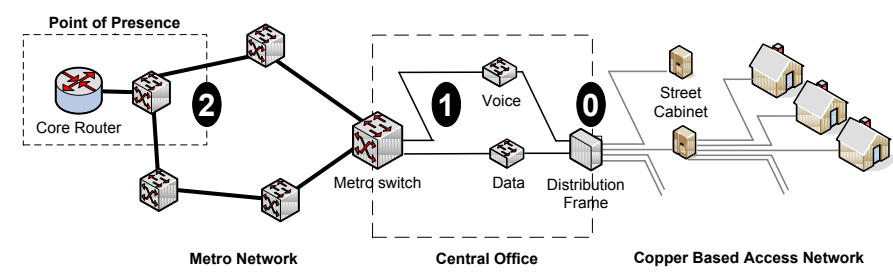

Figure 1 Network overview with unbundling locations [5]

The regulated prices for these access types are one of the main tools NRAs have at their disposal to influence the retail market for broadband access. Decreasing these prices is believed to decrease the entry barrier for OLOs, which should increase the competition on the retail market. Resulting from this increased competition, a price pressure on retail offers could be observed [2]. A secondary effect is the push towards more profitable investments for the incumbent. As their profit margins on the existing copper broadband market decrease, they will look towards NGAN investments.

\section{B. Regulation and network evolution - a difficult interaction}

Although such effects will most certainly play, other authors have argued that a decrease of wholesale access prices could have negative effects on NGAN investment [3], [4]. Expected revenues play a major role in the economic viability of new investment projects. If these remain too low, the investment can be abandoned. With price pressure on copper retail prices, and a higher required ARPU for NGAN investments to be profitable, the price gap between both offers could increase, pushing customers towards the cheaper offer. As such, the expected uptake of the NGAN offer and the resulting payoff could decrease drastically, resulting in a postponement of NGAN investment. 
Therefore, it is very important to have adequate prediction tools to assess the impact of regulatory decisions. In the following paragraph, both existing BPIs and a more NGAN oriented BPI will be used to indicate the possible impact of LLU price changes.

\section{MEASURING BROADBAND PERFORMANCE}

In the Digital Agenda, which was already introduced before, Europe indicates the focal points for any digital advances. As indicated, it covers a variety of goals, ranging from higher access speeds, better broadband coverage and more frequent use of eServices. The Digital Agenda offers a clear view on the different important aspects for NRAs in their national broadband policy, but offers no quantification possibilities or descriptions making its use as a comparative index impossible.

Additionally the Digital Agenda is also missing the aspect of competition, while this is also of key importance in European and national broadband policy. The copper incumbents have been forced to open up their network to OLOs, and reducing the significant market power (SMP) continues to be a key objective. Focussing policy on the Digital Agenda goals while neglecting their impact on competition should be avoided. It has been shown that monopoly or oligopoly typically results in market power for suppliers, reducing the optimal output quantity and sell it at higher prices, thereby reducing the consumer surplus [6].

Translating the Digital Agenda into a ready to use performance indicator is not straightforward. Policy makers need to measure the national performance on each aspect of the Digital Agenda. Some dimensions, like the number of people using eGovernment or eCommerce, might be hard to quantify objectively. Even when all indicators are measured, it still remains unclear how these different aspects add up. Which aspect is the most important to attain? Is broadband coverage the most important, or is it eServices use? Additionally, the Digital Agenda does not allow for a comparison between different scenarios (e.g. simulation outcomes, regions or countries, etc.).

As a starting point the predecessor of the Digital Agenda was studied. The broadband performance index (BPI) was introduced in 2008 to benchmark the overall performance of Member States on a range of factors [7]. These factors include speeds, rural coverage, affordability, innovation and other socio-economic dimensions. More importantly, it also takes into account the competition as it includes a competitioncoverage indicator. Its description covers an extended calculation method, complete with weight factors of the different dimensions, to come to one number reflecting broadband performance. Normalisation through re-scaling is used, according to equation 1 below. The weight factors were discussed between the European Commission and NRAs in order to best reflect the importance of each dimension.

$$
I_{c i}=\frac{x_{c i}-\min _{c}\left(x_{i}\right)}{\max _{c}\left(x_{i}\right)-\min _{c}\left(x_{i}\right)}
$$

The BPI offers an easy to use quantitative PI to assess broadband performance; still its definitions are outdated and no longer applicable to predict the impact of regulatory decisions on nowadays broadband market. Using this PI without any updates or changes can easily lead to incorrect conclusions and faulty policies failing to achieve what was aimed for. In the following sections, we will show how to update this PI to capture more reliably the current market and new advances in access networks

\section{AN NGAN ORIENTED BPI}

The previous section clearly indicated that a good broadband performance index in which current and next generation technologies and the market functioning (e.g. competition and pricing) are included is currently missing. In this paper we will propose a new broadband performance index for which we start from the original BPI and make changes where necessary. In this section we indicate the different updates made to the original BPI. Each dimension of the BPI will be elaborated on, and each change will be motivated.

\section{A. Broadband rural coverage}

The rural coverage of broadband is the first dimension of the BPI, with a weight factor of $12.8 \%$. For this parameter, it is important to define both broadband and rural coverage. In the original BPI, broadband was defined as access speeds over $2 \mathrm{Mbps}$. It may be clear that the introduction of NGAN will not improve this indicator, while this goal is present in the Digital Agenda. Additionally, NGAN is expected to be introduced in the more dense areas, since these areas offer the best business case.

This definition should be altered towards NGAN coverage. We propose to define NGAN in the updated index as a network offering access speeds over $30 \mathrm{Mbps}$ in the line of the Digital Agenda. This means that it includes both the upgrade of existing cable and copper networks as the rollout of FttX networks. A future BPI should base its definition of broadband threshold on objective measurable data. This could for instance be calculated using a formula based on the maximum deployed access speeds and on attainable speeds with next generation technologies. Depending on the considered scenario and regulatory focus, the definition of rural coverage can be maintained, or could be relaxed to full coverage including deployments in urban areas. In case of optical access networks, it was already indicated that rollout will initially focus on urban areas. Relaxation means that when NGAN is rolled out in urban areas, this also improves the broadband performance of the area.

\section{B. Competition coverage}

Above, we discussed the importance of a PI taking into account the different policy goals of NRAs. This dimension was included in the BPI, weighted at $16.7 \%$. Competition coverage is the combination of two factors, namely the market share of new entrants and national coverage. In this definition, it is important to define what a new entrant is. OLOs can clearly be seen as new entrants, especially since their total market share in most markets is very limited. However, the BPI also includes cable operators in the new entrants segment. While this may hold for most cases, some exceptions should be 
allowed. For example, in Flanders, the cable operator currently holds a market share of around $55 \%$ of all broadband users, while the former monopolist only holds $40 \%$ [8]. In this case, the cable operator can no longer qualify as a new entrant.

The BPI should be altered to only include real OLOs with a non-significant market share. Additionally, when NRAs should decide to open up the cable network to OLOs as well, the market share of those operators should also be included in this dimension [9].

\section{Broadband price}

Broadband price is the umbrella covering three different dimensions of broadband pricing, to reflect the affordability of broadband. The first dimension is the median broadband price, corrected for speed (weight $=8.7 \%$ ). This indicator is retained for the NGAN oriented BPI, with a minor change in the calculation method: the median is changed for the average price, which will allow using this index in more specific smaller scale (e.g. city networks) situations and theoretically abstracted (e.g. with less offers) studies. The two other dimensions of the broadband price are the average price for broadband slower than $2 \mathrm{Mbps}$ and for broadband offering speeds between 2 and $8 \mathrm{Mbps}$ (weights $3.8 \%$ and 3.4\% resp.). While these were the typical speed baskets when the BPI was first launched, technological evolution has resulted in raising access speeds, towards $50 \mathrm{Mbps}$ or even higher. Leaving these speeds out of the analysis would neglect the positive impact of network investments. Therefore, the speed baskets should be updated towards more future proof baskets, in which the 'low' speed baskets represent all offers under $30 \mathrm{Mbps}$, while all retail offers with NGAN speeds are classified in the 'high' speed basket. As mentioned before the broadband threshold of $30 \mathrm{Mbps}$ is based on the Digital Agenda and should be continuously updated.

\section{Speeds}

Coverage, competition and affordability were all covered in the previous parameters of the updated BPI. However, as the introduction of NGAN speeds to end consumers will most likely result in an increased uptake of advanced services, speed is also an important dimension of the BPI, split up in two separate parameters.

The average speed is the first indicator (weight $=9.8 \%$ ). It may be clear that with more NGAN being rolled out and taken up, the value of this indicator will rise. We therefore choose to retain this dimension in the NGAN oriented BPI. However, the second indicator, the percentage of subscribers with access speeds over $2 \mathrm{Mbps}$, is no differentiator towards NGAN (weight $=8.3 \%$ ). For example in Belgium, almost $100 \%$ of the country is covered with DSL services, so upgrading the network towards NGAN would have no impact on this aspect. But when translating the Digital Agenda goals, which aim at full coverage of $30 \mathrm{Mbps}$, the change to this parameter is quite straightforward. The speed dimension in the NGAN oriented BPI should include both average speed and coverage of 30 Mbps (or again the broadband threshold).

\section{E. Other dimensions}

The original BPI also includes dimensions like the take-up of advanced services and the socio-economic context (weights 19.6 and 17.4 resp.). Advanced services was interpreted as the number of customers using eServices, like eGovernment, eCommerce or eBanking. Socio-economic factors include ICT spending and PC penetration. We believe it is important to also include such parameters to assess the impact of regulatory decisions. However, when using performance indices to predict the impact of regulatory decisions, the quantification of these parameters would come with a large amount of work and a high degree of uncertainty. Therefore, these dimensions are left out of the analysis further in this paper. For a visual comparison of the original BPI and the new NGAN oriented BPI, we refer to Figure 2 and 3. 


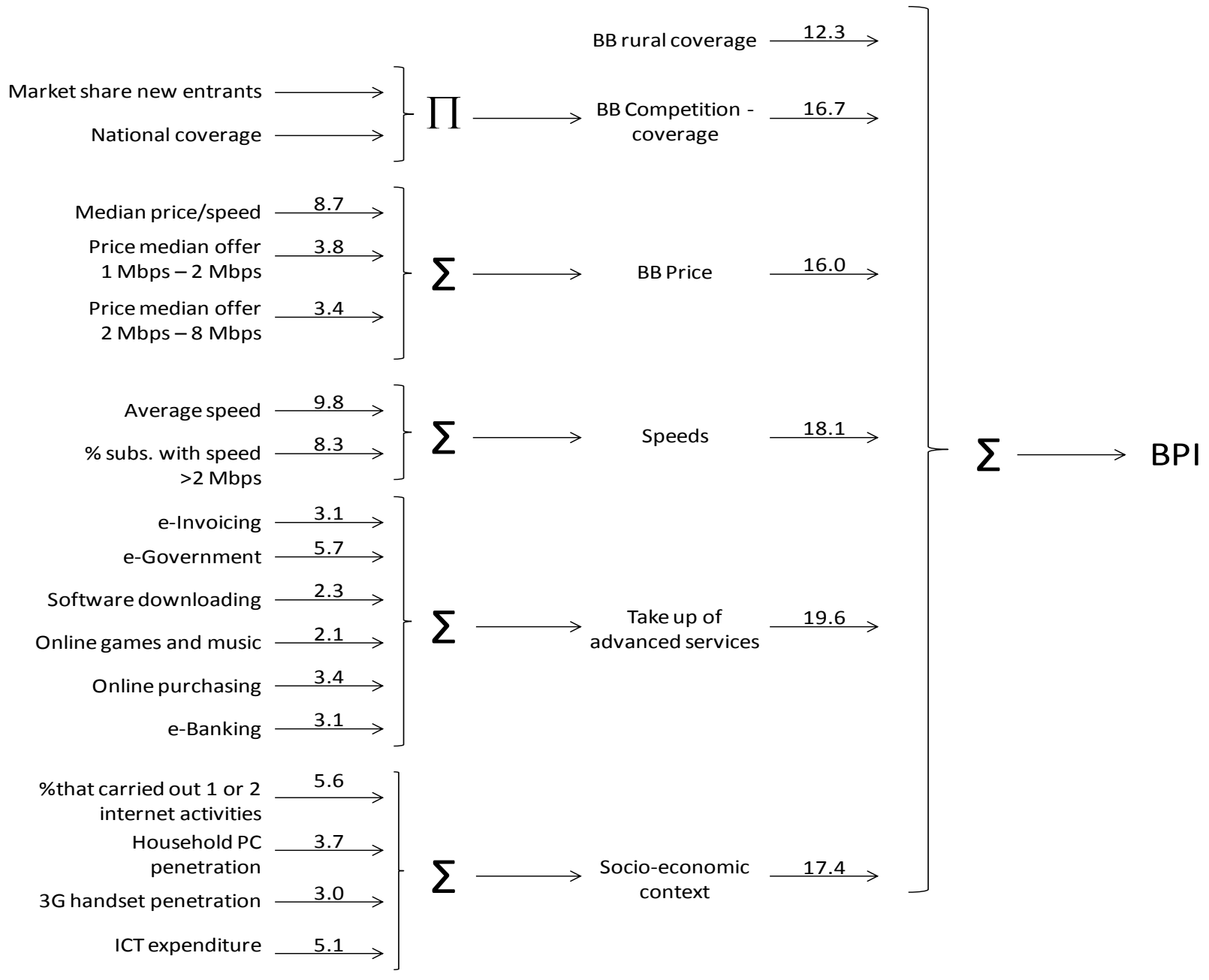

Figure 2: From the broadband performance index

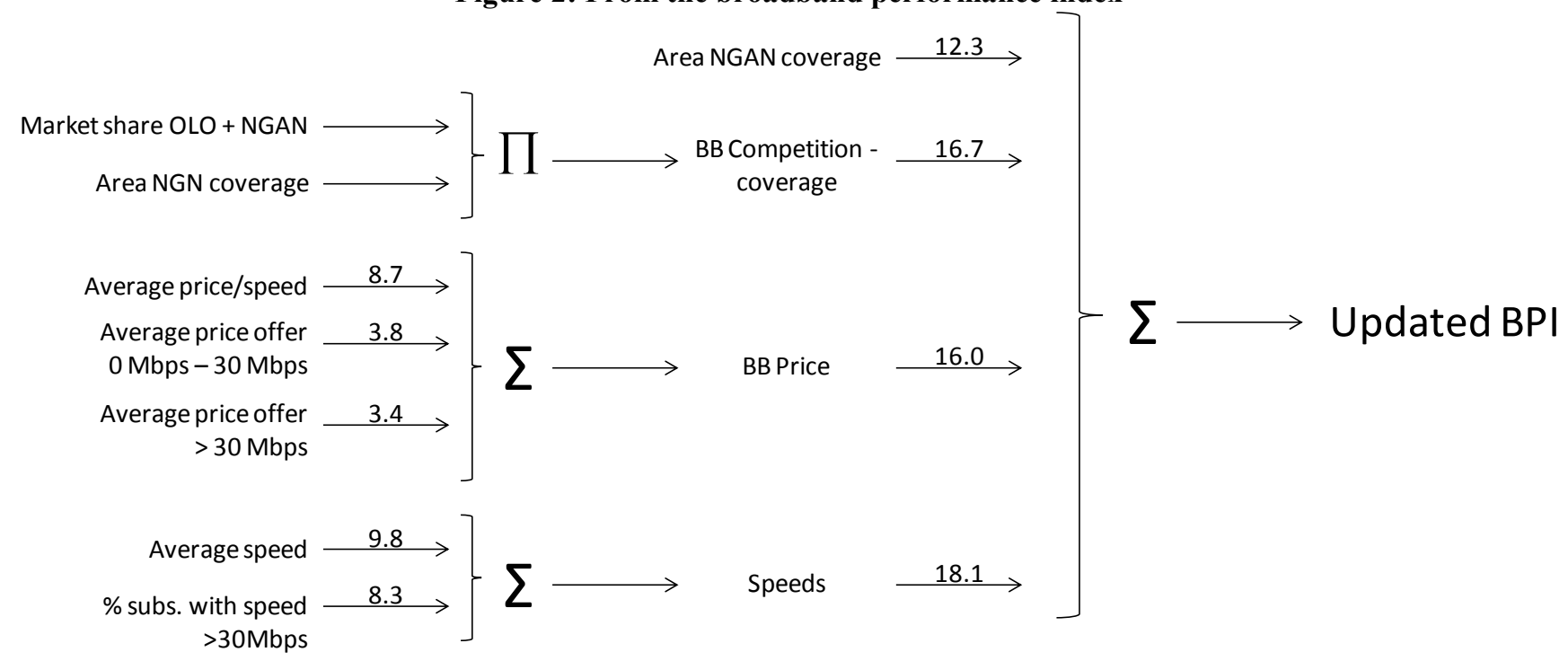

Figure 3: To an NGAN oriented BPI 


\section{ASSESSING THE IMPACT OF REGULATORY DECISIONS}

To clearly indicate the need for a NGAN oriented performance index, the evolution of both indices, the existing and updated BPI will be evaluated under two change scenarios. As a benchmark scenario, the current situation in Belgium will be assessed. The two exemplary future scenarios comprise a scenario where the regulator lowers LLU prices and a scenario where an important increase in NGAN deployment is assessed. In both scenarios, the impact on the broadband performance (both original and updated BPI) is calculated and compared.

\section{A. Current broadband performance in Belgium}

Belgium is characterised by both high broadband coverage and take-up. In 2011, the number of households with a broadband connection was around $81 \%$. Two large players can be identified in this market, the incumbent holding a market share of $42 \%$ and the cable operator claiming $47 \%$ of the market. The remainder of the broadband market is in hands of OLOs [9].

Operators are currently upgrading their network towards NGAN, and $30 \%$ of the customers already have download speeds over $30 \mathrm{Mbps}$. Retail prices for these offers can be found in Table 1 below, current access speeds in Table 2.

Rural coverage of broadband according to the definition used in the existing BPI is $100 \%$. We assume $50 \%$ coverage of NGAN.

Table 1 Average broadband retail prices in Belgium

\begin{tabular}{|l|l|}
\hline Provider & Retail price (excl. VAT) \\
\hline OLO & $€ 27$ \\
\hline Cable & $€ 29$ \\
\hline Incumbent & $€ 28.6$ \\
\hline NGAN & $€ 37$ \\
\hline
\end{tabular}

Table 2 Current broadband speeds and market shares [9]

\begin{tabular}{|l|l|}
\hline Speed basket & Market share \\
\hline$<2 \mathrm{Mbps}$ & $2 \%$ \\
\hline $2-10 \mathrm{Mbps}$ & $29 \%$ \\
\hline $10-30 \mathrm{Mbps}$ & $39 \%$ \\
\hline $30-100 \mathrm{Mbps}$ & $28 \%$ \\
\hline$>=100 \mathrm{Mbps}$ & $2 \%$ \\
\hline
\end{tabular}

Table 3 Market share of the different offers

\begin{tabular}{|l|l|}
\hline NGAN & $30 \%$ \\
\hline Non NGAN incumbent & $29.4 \%$ \\
\hline Non NGAN cable & $32.9 \%$ \\
\hline Non NGAN OLO & $7.7 \%$ \\
\hline
\end{tabular}

These inputs allow calculating the value of the existing and updated BPI for the current situation. Notice that we leave out the socio-economic factors and take-up of advanced services in the existing BPI as well.

Table 4 shows the results for the existing and updated BPI for the current situation, which serve as benchmark scenario.

Table 4 Current broadband performance in Belgium

\begin{tabular}{|l|l|}
\hline Performance index & Value \\
\hline Existing BPI & 0.2430 \\
\hline Updated BPI & 0.5732 \\
\hline
\end{tabular}

\section{B. Impact of scenarios on broadband performance}

Two different scenarios were indicated above. In the first scenario, the regulator drops the LLU price significantly with the aim to stimulate competition, the second focuses on assessing correctly the impact of broadband.

\section{1) Decrease of $L L U$}

The impact of the first action in this stylized example is as follows. A decrease in the LLU price is directly reflected in the retail price of the different offers. Currently, the LLU price in Belgium is set at $€ 8.03$ per line per month. In addition, it is expected to influence the take-up of OLO services. For this example, we expect that a decrease of the LLU price with $€ 3$ increases the market share of the OLO with 2 percent point, equally reducing the market shares of the incumbent and cable operator. As the broadband market is typically considered to be very inelastic, a significant drop in total broadband customers is not expected for a price cut of $€ 3(10 \%)$ and we neglected this effect. The resulting BPIs and the relative change compared to the existing situation can be found in Table 5.

Table 5 Impact of decreasing the LLU price

\begin{tabular}{|l|l|l|}
\hline Performance index & Value & Change \\
\hline Existing BPI & 0.2459 & $+1.19 \%$ \\
\hline Updated BPI & 0.5830 & $+1.71 \%$ \\
\hline
\end{tabular}

It is clear that the effect of increased competition is reflected in both performance indices. This is a combined effect of both the lowered prices and the increased market share of OLOs. If the LLU price decrease would only have an effect on the prices, but not on the market shares, the BPI increase would only be $0.08 \%$ and $1.33 \%$ for the existing and updated BPI respectively. Both BPIs clearly assess the impact of increased competition and decreasing retail prices correctly.

It has been argued that decreasing the LLU price would have a negative effect on the take-up of NGAN products and services, due to the increased price gap between the NGAN and non-NGAN offers. In this scenario, the NGAN price remains unchanged compared to the current situation, resulting in a decreased market share. We assume a decrease of $6 \%$, which is equally attributed to the three other players. We leave out the effect of increased OLO take-up to filter this impact from the BPIs. As can be seen from Table 7, this change has a 
negative effect on both BPIs. If decreasing the LLU price would indeed force consumers from more expensive NGAN products towards the cheaper existing products, the broadband performance of the region will decrease. Of course, this effect is most pronounced in the NGAN oriented updated BPI.

Table 6 Market shares after LLU price decrease

\begin{tabular}{|l|l|}
\hline NGAN & $24 \%$ \\
\hline Non NGAN incumbent & $31.4 \%$ \\
\hline Non NGAN cable & $34.9 \%$ \\
\hline Non NGAN OLO & $9.7 \%$ \\
\hline
\end{tabular}

Table 7 BPI changes from decrease in NGAN market

\begin{tabular}{|l|l|l|}
\hline \multicolumn{2}{|c|}{ share } & Change \\
\hline Existing BPI & Value & $-0.7 \%$ \\
\hline Updated BPI & 0.2413 & $-10 \%$ \\
\hline
\end{tabular}

If all the effects described above are combined, i.e. a lower retail price for all offers (except NGAN), a decrease in market share for NGAN and an increase of the OLO market share, the total effect on the BPIs shows a different view (Table 8). The effect of increased competition outweighs the decrease in NGAN take-up in the existing BPI. For the updated BPI, there is clearly a detrimental effect on the broadband performance due to decrease in the NGAN take-up. This example clearly indicates that the possible side effects of reducing the LLU price might go unnoticed for the regulator if he does not take the NGAN deployment and uptake into account in his measurements.

Table 8 Combined effect of LLU price decrease on broadband performance

\begin{tabular}{|l|l|l|}
\hline Performance index & Value & Change \\
\hline Existing BPI & 0.2546 & $+4.77 \%$ \\
\hline Updated BPI & 0.5269 & $-8.08 \%$ \\
\hline
\end{tabular}

\section{2) Increase of $N G A N$}

In this section, the rationale from [3] is implemented in the BPI models. The LLU price is maintained, so no retail price effects are observed. Additionally we consider an increase in the NGAN coverage to $90 \%$. The effect of increased NGAN coverage is shown in Table 9. Since this dimension is not included in the existing BPI, no effect of increased coverage is observed. However, the updated BPI shows a significant increase. When taking into account that increased NGAN coverage will most likely also influence the take-up of those services, the effect is even more pronounced. An increase of 10 percent point NGAN take-up together with increased coverage results in a $36 \%$ increase of broadband performance according to the updated BPI. This means that any simulation or measurement of the broadband performance using the original BPI, of an area in which NGAN has only recently been deployed, will totally miss the positive effect of this rollout. As uptake of NGAN network services follows an S-shaped curve, it could take some time before a market switch is happening and as such before the positive effects get noticed through an increased uptake of NGAN.

Table 9 BPI changes due to increased NGAN coverage

\begin{tabular}{|l|l|l|}
\hline Performance index & Value & Change \\
\hline Existing BPI & 0.2430 & $/$ \\
\hline Updated BPI & 0.6627 & $+15.61 \%$ \\
\hline
\end{tabular}

Table 10 Combined effect increased NGAN coverage and take-up

\begin{tabular}{|l|l|l|}
\hline Performance index & Value & Change \\
\hline Existing BPI & 0.2507 & $+3.17 \%$ \\
\hline Updated BPI & 0.7794 & $+35.97 \%$ \\
\hline
\end{tabular}

Clearly basing regulatory actions on simulations and calculations using the original BPI could lead to detrimental side effects once implemented. It is essential to measure, both in simulation as well as after implementation of regulatory actions, the different effects using an index taking into account both competition as well as NGAN deployment and uptake.

\section{CONCLUSIONS AND FUTURE WORK}

Measuring broadband performance is a difficult task for national regulatory authorities. Coverage, prices, speeds and competition are different dimensions of the concept broadband performance. Not only are those parameters not always straightforward to measure, when NRAs try to increase broadband performance, interacting effects between the different dimensions have to be taken into account. Focussing on increased competition and lower retail prices could decrease the take-up of NGAN or vice versa.

In order to adequately measure the national broadband performance, performance indices need to be developed who can take these interacting effects into account. In this paper, two existing performance indices were described. The Digital Agenda is the most future oriented PI, but lacks quantification possibilities. The existing BPI allows quantifying broadband performance, while taking into account the interaction effects between the different dimensions. However, since the existing BPI works with outdated definitions of broadband, and leaves out any impact of NGAN, a NGAN oriented BPI was developed in this paper, starting from the existing BPI. In order to assess the performance of both PIs in a regulatory setting, they were applied to a hypothetical case study in Belgium.

The impact of LLU price was taken as an example. Two different viewpoints on the effect of such changes have been studied. In the first scenario, the rationale that lower LLU stimulates competition was taken. Both PIs show that this effect translates into a higher broadband performance. However, when these lower LLU prices also influence the take-up of NGAN, and drive consumers towards the cheaper offers, the positive effect of increased competition is offset by 
the decreased NGAN take-up. However, when using the existing BPI, this has a positive effect on the broadband performance. When correcting this PI to include NGAN, the effect is clearly negative. These results show the importance of including future oriented measures in performance indices, especially if they are used to estimate the impact of regulation.

The second scenario covered the impact of NGAN rollout on broadband performance. Since this dimension is left out in the existing BPI, no impact was observed. When using the updated BPI, there is however a clear impact of such a rollout on broadband performance, which is even more significant if this also results in higher NGAN uptake.

In this paper, it has been shown that performance indices can also be used to predict the impact of regulation, if the correct PIs are chosen. In future work, the updated BPI developed in this work can be used in research assessing the impact of regulation on price and investment strategies of the broadband operators in a certain geographic region. As such, it is possible to study the equilibrium outcome where different players try to maximize their payoff, being it profit for operators or social welfare for NRAs.

\section{REFERENCES}

[1] European Commission, $A$ digital agenda for Europe. Publications Office, 2010, p. 42

[2] S. Hoernig, S. Jay, W. Neu, K. Neumannn, T. Plückebaum, and I. Vogelsang, "Wholesale pricing, NGA take-up and competition," 2011

[3] B. Williamson, D. Black, and J. Wilby, "Costing methodology and the transition to next generation access," 2011

[4] R. W. Crandall, J. A. Eisenach, and A. T. Ingraham, "The Long-Run Effects of Copper Unbundling and the Implications for Fiber," no. March, pp. 1-55, 2012.

[5] K. Casier, M. Tahon, M. Bilal, S. Verbrugge, D. Colle, M. Pickavet, and P. Demeester, "Estimating the economic value of flexibility in access network unbundling," in NETWORKING 2010, 2010, pp. 362-372.

[6] A. P. Lerner, "The Concept of Monopoly and the Measurement of Monopoly Power," The Review of Economic Studies, vol. 1, no. 3, pp. $157-175,1934$

[7] European Commission, "Indexing broadband performance," 2008.

[8] BIPT, CSA, Medienrat.be, and VRM, "Beslissing van de regulatoren voor de elektronische communicatiesector (CRC) van juli 2011 met betrekking tot de analyse van de breedbandmarkten," 2011
BIPT, "Situatie van de elektronische communicatiesector 2011," 2011. 